\title{
Recuperação Fecal de Indicadores Internos Avaliados em Ruminantes
}

\author{
Lúcia Maria Zeoula ${ }^{1}$, Ivanor Nunes do Prado ${ }^{1}$, Paulo Henrique Moura Dian², \\ Luiz Juliano Valério Geron ${ }^{3}$, Saul Ferreira de Caldas Neto ${ }^{4,5}$, Emylin Midore Maeda ${ }^{3}$, \\ Paula Dal Pra Peron ${ }^{2}$, Jair de Araujo Marques ${ }^{4}$, Alencariano José da Silva Falcão ${ }^{4}$
}

\footnotetext{
RESUMO - Foi determinada a recuperação fecal de quatro indicadores internos: cinza insolúvel em ácido (CIA), cinza insolúvel em detergente ácido (CIDA), fibra em detergente ácido indigestível (FDAI) e fibra em detergente neutro indigestível (FDNI) e a digestibilidade aparente da matéria seca (MS) e da matéria orgânica (MO). Foram utilizados quatro ovinos castrados, alimentados com quatro níveis de substituição do milho pela farinha de varredura. As amostras dos alimentos, sobras e fezes foram incubadas in situ, durante 192 horas, em três vacas Holandesas, portadoras de cânula de rúmen para determinar as fibras em detergente neutro e ácido indigestíveis. As recuperações fecais da CIA e da FDNI não diferiram de 100\% e apresentaram para os coeficientes de digestibilidade de MS e MO valores semelhantes àqueles obtidos pelo método de coleta total. A recuperação fecal da CIDA e FDAI diferiu de 100\%.
}

Palavras-chave: cinza insolúvel em ácido, cinza insolúvel em detergente ácido, fibra em detergente ácido indigestível, fibra em detergente neutro indigestível

\section{Fecal Recuperation of Internal Markers in Assay with Ruminants}

\begin{abstract}
This experiment was carried out to assess the fecal recuperation of the following internal markers: acid insoluble ash (AIA), acid detergent insoluble ash (ADIA), indigestible acid detergent fiber (IADF), indigestible neutral detergent fiber (INDF), and the apparent digestibility of dry matter (DM) and organic matter (OM). Four castrated sheep were used, fed with four levels of substitution of corn by cassava by-product meal. The feed samples, orts and feces were incubated in situ for 192 hours in three Holstein cows with ruminal cannula to determine the indigestible neutral detergent fiber and indigestible acid detergent fiber. The fecal recuperation of AIA and INDF were not different from $100 \%$ and had values for the digestibility coefficient of DM and OM similar to those obtained by the total feces collection method. The fecal recuperation of ADIA and IADF differed from $100 \%$.
\end{abstract}

Key Words: acid insoluble ash, acid detergent insoluble ash, indigestible acid detergent fiber, indigestible neutral detergent fiber

\section{Introdução}

Os indicadores têm sido utilizados como ferramenta experimental por muitos anos (Merchen, 1993) e um amplo número de substâncias tem sido avaliado como indicador para estudar a função digestiva em ruminantes. $\mathrm{O}$ indicador pode ser interno, aquele que ocorre naturalmente no alimento ou externo que é adicionado na ração ou administrado oral ou intraruminalmente.

Tem-se discutido muito sobre o assunto, mas os pesquisadores não encontraram ainda, uma substância com características de indicador perfeito ou definir qual componente químico que se assemelha mais com aquelas desejadas. Segundo Merchen (1993), nenhuma das substâncias usadas como indicador preenchem todas as características, mas várias são suficientemente adequadas para fornecer dados significativos. Por esta razão, a procura de indicadores ideais constitui um dos assuntos de grande interesse na pesquisa de técnicas que facilitem estudos de nutrição animal. Nos últimos anos têm sido proposto várias substâncias ou novos métodos de análises que superariam algumas das limitações anteriores (Piaggio et al., 1991).

Sein \& Todd (1988) compararam o método da cinza insolúvel em ácido (CIA) e da lignina em detergente ácido com o método de coleta total, na estimativa dos coeficientes de digestibilidade, em ovinos alimentados com várias dietas. Estes autores verificaram que somente em dois dos dezessete ensaios de digestibilidade realizados, os resultados obti-

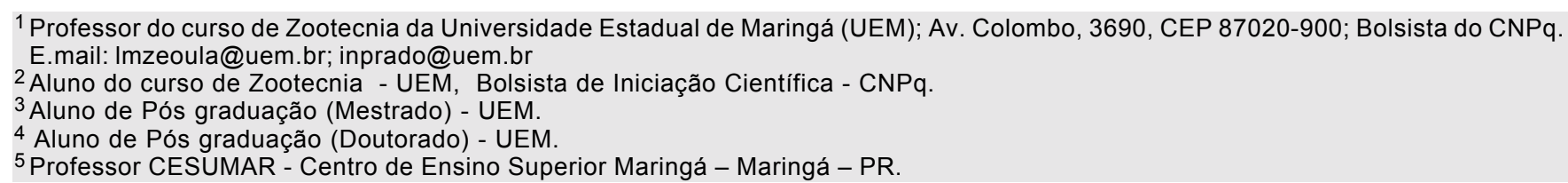


dos pelo método da CIA diferiram daqueles obtidos pelo método de coleta total. Observaram ainda, que houve maior variação da recuperação do indicador nas fezes para CIA, quando os ovinos consumiram rações com cevada.

Piaggio et al. (1991) utilizaram ovinos alimentados com feno de alfafa e consumo restrito $(90 \%$ do ad libitum) com teor de CIA de $1,05 \%$ na MS da ração e obtiveram percentagem de recuperação fecal de CIA de $83,8 \% \pm 19,2 \%$, diferindo de $100 \%$, pelo método de coleta total. Concluíram que a alta variação nas percentagens de recuperação é devida, principalmente, ao teor e a composição da CIA do alimento, que interagem entre si.

A recuperação fecal dos indicadores CIA, cinza insolúvel em detergente ácido (CIDA) e óxido crômico, em novilhos alimentados com rações contendo $30 \mathrm{ou}$ $50 \%$ de concentrado, foi verificada por Fontes et al. (1996). Os autores obtiveram valores médios de recuperação de CIA próximo de $100 \%$, independentemente do teor de concentrado na dieta, com o máximo de 105,1 e o mínimo de 102,4\%. Os teores de CIA nas rações foram de 2,7 e 1,1\% para rações com 30 e $50 \%$ de concentrado, respectivamente.

$\mathrm{O}$ uso de CIA tem mostrado resultado contraditório na estimativa dos fluxos de MS fecal, ora subestimando ora superestimando seus coeficientes de digestibilidade (Zeoula, et al., 1994; Berchielli et al., 2000; Zeoula et al., 2000).

Assim como a CIA, a CIDA pode ser usada como indicador para determinar a digestibilidade, no entanto, muito pouco tem sido publicado sobre seu uso como indicador. Sherrod et al. (1978) observaram, em caprinos e bovinos, que a digestibilidade determinada a partir da CIDA não diferiu dos valores da coleta total quando a ração apresentava $3,0 \%$ de cinza e relataram que níveis menores subestimaram os coeficientes de digestibilidade.

Segundo Oliveira et al. (1991), a CIDA mostrou-se confiável para estimar a digestibilidade, para teor médio de 1,2\% de CIDA na MS da ração, em período de 4 dias de coleta de fezes. O teor de $1,9 \%$ de CIDA na MS da ração foi considerado satisfatório por Carvalho et al. (1992), obtendo valores médios de recuperação próximos de $100 \%$, com o máximo de $114,3 \%$ e o mínimo de $73,8 \%$. Também Fontes et al. (1996), trabalhando com rações, em média, com $2,0 \%$ de CIA na MS, obtiveram bons resultados de recuperação fecal de CIDA. Estes autores verificaram valores que va- riaram de 96,5 a 102,5\%, não diferindo de $100 \%$, o que sugere que este componente apresenta potencial para estudos de digestibilidade em ruminantes.

Zeoula et al. (1994), trabalhando com ovinos alimentados com rações com 1,5\% de CIDA na MS, em consumo voluntário e consumo restrito, obtiveram valores de recuperação fecal de 140,8 e 114,2\%, respectivamente. Os autores concluíram que estes resultados propiciaram uma superestimativa dos coeficientes de digestibilidade da MS, em comparação ao método de coleta total de fezes.

O uso da fibra em detergente neutro indigestível (FDNI) tem mostrado resultados promissores como indicador interno. Lippke et al. (1986) afirmaram que a fibra indigestível, sendo adequadamente medida, poderia ser um indicador interno útil para estimar a digestibilidade em experimentos de pastejo. De modo geral, nas rações, os teores de CIA geralmente são baixos, ocorrendo aumento no desvio-padrão. Este erro padrão poderia ser reduzido se um componente indigestível de maior porcentagem na MS pudesse ser encontrado e, segundo Van Soest (1994), a FDNI tem sido utilizada com este propósito.

O uso da FDNI em ensaios de digestibilidade tem mostrado resultados semelhantes aos obtidos com a cutina (Ezequiel et al.,1999). Superestimativas de fluxo de MS duodenal e fecal foram observadas com a FDNI, resultando em coeficientes de digestibilidade subestimados (Ítavo et al., 2001a; Zeoula et al., 2000). Por outro lado, a FDNI em comparação com outros indicadores, como a fibra em detergente ácido indigestível (FDAI), óxido crômico e cloreto de itérbio foi avaliada por Berchielli et al. (1998) que observaram que a FDNI e a FDAI apresentaram menor variação e não diferiram entre si quanto à determinação da digestibilidade, enquanto os indicadores externos superestimaram os fluxos de MS e MO duodenal.

Saliba et al. (1999) compararam a FDAI, a lignina isolada da palha de milho (LPM-RM), o óxido crômico $\left(\mathrm{CR}_{2} \mathrm{O}_{3}\right)$, o cloreto de itérbio $\left(\mathrm{YbCl} 3.6 \mathrm{H}_{2} \mathrm{O}\right)$, a metoxila da lignina $\left(\mathrm{OCH}_{3}\right)$, a lignina Klasson (LK) e a lignina determinada por espectroscopia no infravermelho (LIG-IV). O coeficiente de digestibilidade obtido com a FDAI foi o mais próximo do valor obtido pela coleta total de fezes $(42,6$ vs $49,7 \%)$. Todos os indicadores foram estatisticamente semelhantes quanto à recuperação fecal, exceto a metoxila que teve baixa recuperação $(44,6 \%)$. Os autores observaram valores de recuperação fecal da FDAI de 114,1\%, comparado à coleta total de fezes.

R. Bras. Zootec., v.31, n.4, p.1865-1874, 2002 
Freitas et al. (2001) compararam os indicadores internos FDNI e FDAI, obtidos após 144hs de incubação in vitro e in situ (FDNiv; FDNis; FDAiv; FDAis) e o óxido crômico como indicador externo, para estimar a produção fecal e o fluxo duodenal de matéria seca em novilhos confinados. Os valores estimados de produção fecal, quando associados aos dados de digestibilidade para estimativa do consumo e sua comparação com o valor determinado através das pesagens diárias, permitiram inferir que o indicador mais adequado foi a FDAI, independentemente do método in vitro e in situ.

Também Ítavo et al. (2001b), comparando os indicadores FDAI e óxido crômico para estimar a produção de matéria seca fecal e os coeficientes de digestibilidade total e parcial da matéria seca das rações de bovinos, observaram que os coeficientes de digestibilidade ruminal e intestinal não diferiram entre indicadores e metodologias de coleta e sugeriram que a FDAI pode ser utilizada como indicador interno para estimar fluxos de matéria seca no abomaso, no íleo e nas fezes.

O objetivo deste trabalho foi o de avaliar a recuperação fecal dos indicadores internos, cinza insolúvel em ácido (CIA), cinza insolúvel em detergente ácido (CIDA), fibra em detergente ácido indigestível (FDAI) e fibra em detergente neutro indigestível (FDNI) e a digestibilidade aparente da matéria seca (MS) e da matéria orgânica (MO) das rações experimentais.

\section{Material e Métodos}

O experimento foi conduzido na Fazenda Experimental de Iguatemi (FEI), no Setor de Digestibilidade de Ruminantes. As análises químicas foram realizadas no Laboratório de Nutrição do Departamento de Zootecnia (DZO) da Universidade Estadual de Maringá (UEM).

Foram utilizados quatro carneiros, machos, castrados, sem raça definida (SRD), com peso médio de $41,3 \mathrm{~kg}$. Os animais foram alojados em gaiolas metabólicas, portando bebedouros e comedouros individuais, para avaliação do consumo individual e coleta total de fezes, durante o período experimental. As fezes foram coletadas através de sacolas de napa especiais adaptadas aos animais.

Para quantificar os indicadores internos presentes nos alimentos, fibra em detergente neutro indigestível (FDNI) e a fibra em detergente ácido indigestível (FDAI), foram utilizadas três vacas da raça Holandesa, pesando em média $550 \mathrm{~kg}$ de PV, com cânula no rúmen.

Para determinação dos coeficientes de digestibilidade aparente de MS das rações experimentais, foram utilizados os indicadores internos, CIA, CIDA, FDAI e FDNI, cuja concentração nos alimentos está mostrada na Tabela 1 .

A FDNI e a FDAI foram determinadas pela extração em detergente neutro e em detergente ácido, respectivamente, nas amostras de alimentos, fezes e sobras depois de 192 horas de incubação in situ.

Tabela 1 - Concentração dos indicadores internos nos alimentos (\% MS)

Table 1 - Concentration of internal markers of food (\%MS)

\begin{tabular}{|c|c|c|c|c|}
\hline \multirow[t]{2}{*}{$\begin{array}{l}\text { Alimento } \\
\text { Food }\end{array}$} & \multicolumn{4}{|c|}{$\begin{array}{l}\% \text { de indicador } \\
\% \text { of in markers }\end{array}$} \\
\hline & $\begin{array}{l}\text { CIA } \\
A I A\end{array}$ & $\begin{array}{l}\text { CIDA } \\
A D I A\end{array}$ & $\begin{array}{l}\text { FDAI } \\
I A D F\end{array}$ & $\begin{array}{l}\text { FDNI } \\
I N D F\end{array}$ \\
\hline $\begin{array}{l}\text { Milho moído } \\
\text { Ground corn }\end{array}$ & 0,02 & 0,73 & 0,32 & 0,78 \\
\hline $\begin{array}{l}\text { Farinha de varredura de mandioca } \\
\text { Cassava by-product meal }\end{array}$ & 0,07 & 0,80 & 5,06 & 5,29 \\
\hline $\begin{array}{l}\text { Farelo de soja } \\
\text { Soybean meal }\end{array}$ & 0,10 & 0,06 & 0,84 & 1,18 \\
\hline $\begin{array}{l}\text { Feno de tifton } 85 \\
\text { Tifton } 85 \text { bermudagrass hay }\end{array}$ & 2,39 & 1,70 & 14,22 & 25,23 \\
\hline
\end{tabular}

CIA: cinza insolúvel em ácido, CIDA: cinza insolúvel em detergente ácido, FDAl: fibra em detergente ácido indigestível, FDNI: fibra em detergente neutro indigestível.

AIA: acid insoluble ash, ADIA: acid detergent insoluble ash, IADF: indigestible acid detergent fiber, INDF: indigestible neutral detergent fiber.

R. Bras. Zootec., v.31, n.4, p.1865-1874, 2002 
Os sacos de náilon utilizados apresentavam poros com $53 \mu \mathrm{m}$ de espessura, com $20 \mathrm{mg}$ de $\mathrm{MS} / \mathrm{cm}^{2}$.

Quatro rações experimentais foram formuladas para atender as exigências nutricionais dos ovinos que apresentavam $11,0 \%$ de $\mathrm{PB}$ e 2,0 Mcal de energia metabolizável (EM)/ $\mathrm{kg}$ MS de acordo com o NRC (1975).

As rações foram compostas de farelo de soja (FS), milho integral triturado, farinha de varredura de mandioca (FV), feno de Tifton 85 (Cynodon dactylun) colhido aos 42 dias. A composição percentual e química das rações experimentais está mostrada na Tabela 2. As quatro rações foram diferenciadas, conforme os níveis de substituição do milho pela farinha de varredura (FV), no concentrado: $\mathrm{R} 25=75 \%$ milho + $25 \% \mathrm{FV} ; \mathrm{R} 50=50 \%$ milho $+50 \% \mathrm{FV} ; \mathrm{R} 75=25 \%$ milho $+75 \% \mathrm{FV}$ e R100 $=100 \% \mathrm{FV}$.

$\mathrm{O}$ volumoso e concentrado utilizados nas rações foram pesados diariamente e fornecidos aos animais. A alimentação dos animais, dividida em duas porções iguais, foi realizada duas vezes ao dia (8 e $16 \mathrm{~h}$ ). Dez gramas de sal mineralizado foram adicionados às rações, na primeira alimentação.

Os animais foram submetidos a 15 dias de adaptação, em cada período experimental, recebendo as rações à vontade. O período de coleta teve duração de sete dias, durante os quais foram coletadas amostras de fezes, alimento fornecido e sobras. Os períodos de adaptação e coleta, assim como os cálculos da digestibilidade total seguiram as recomendações descritas por Coelho da Silva \& Leão (1979).

A média de consumo de cada animal durante os últimos cinco dias do período de adaptação foi calculada; a esse valor médio foi feito um acréscimo de $20 \%$, permitindo que houvesse sobras nos comedouros durante o período de coleta.

Tabela 2 - Composição percentual e química das rações experimentais (\% MS)

Table 2 - Percentual composition and chemical of the experimental diets (\%DM)

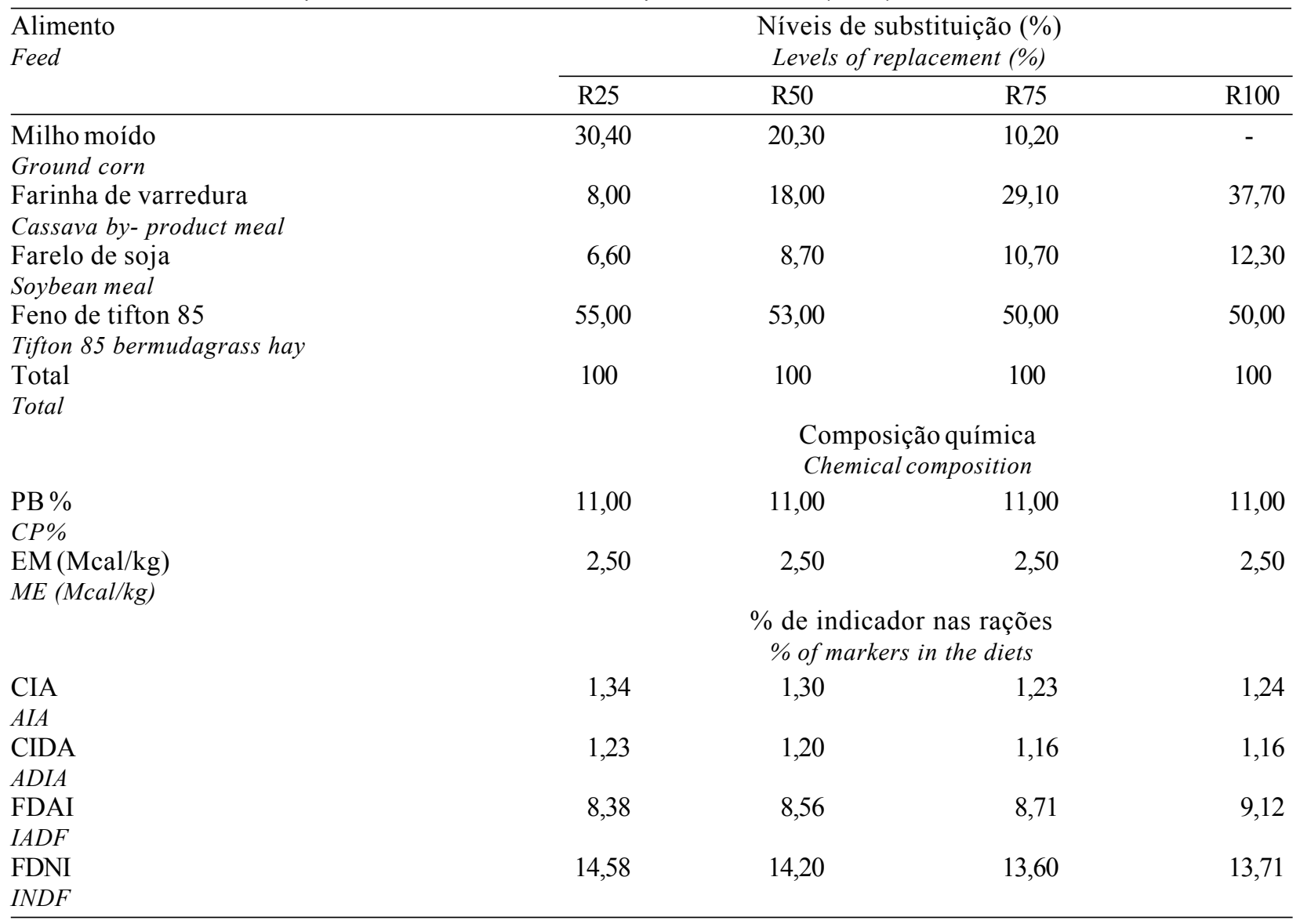

R25, R50, R75 e R100: respectivamente, 25, 50, 75 e 100\% de farinha de varredura em substituição ao milho. CIA: cinza insolúvel em ácido, CIDA: cinza insolúvel em detergente ácido, FDAI: fibra em detergente ácido indigestível, FDNI: fibra em detergente neutro indigestível. PB: proteína bruta

R25, R50, R75 and R100: respectively, 25, 50, 75 e 100\% of cassava by-product meal in substitution for corn. AIA: acid insoluble ash, ADIA: acid detergent insoluble ash, IADF: indigestible acid detergent fiber, INDF: indigestible neutral detergent fiber. CP: crude protein 
Os animais foram submetidos a três dias de adaptação às sacolas de napa para coleta de fezes, no início do período experimental. No início e final de cada período, os animais foram pesados, tomando-se o peso médio para cálculo do peso metabólico $(\mathrm{kg} 0,75)$.

As sobras de alimentos foram pesadas pela manhã em sua totalidade, sendo $10 \%$ amostrado e armazenadas em sacos plásticos com as respectivas identificações dos animais, tratamento e período de coleta. Essas amostras diárias foram reunidas em uma amostra composta por período de coleta.

A partir de 48 horas do início de cada período de coleta, as fezes eram retiradas das sacolas duas vezes ao dia para propiciar melhor conforto aos animais, sendo retirada uma alíquota de $10 \%$ do total excretado durante 24 horas, após homogeneização do material. Essas amostras diárias (seis dias) foram reunidas em uma amostra composta por animal e período de coleta, armazenadas em sacos plásticos devidamente identificados e congeladas $\left(-10^{\circ} \mathrm{C}\right)$.

Terminados os períodos experimentais, as amostras de alimentos, sobras e fezes, ensacadas e congeladas, foram submetidas ao descongelamento até atingirem a temperatura ambiente. As amostras de fezes foram homogeneizadas e uma amostra composta foi retirada por animal. Em seguida, essas amostras foram pesadas em recipientes de alumínio de pesos conhecidos e levadas para estufa com ventilação forçada a $55 \pm 5^{\circ} \mathrm{C}$, por 72 horas.

As fezes secas, sobras e o feno de tifton 85, foram moídos individualmente três vezes num moinho de facas sem peneira e misturados em quantidades iguais, para formar amostras compostas de fezes, sobras e feno, por animal. Parte destas amostras compostas foi separada para incubação no rúmen, para determinação da FDNI e FDAI, e a outra parte foi moída no moinho de facas com peneira de $1 \mathrm{~mm}$, para realizar as análises de CIA e CIDA.

O cuidado no tamanho das partículas das amostras de fezes, sobras e alimentos para determinação da FDAI e FDNI foi observado com o objetivo de não haver perdas pelos poros dos sacos de náilon, quando da incubação in situ.

Foram determinados os teores de matéria seca em estufa a $105^{\circ} \mathrm{C}$ e os teores de CIDA, FDNI, FDAI foram determinados, segundo metodologias citadas por Silva (1990). As análises de CIA foram realizadas de acordo com a metodologia proposta por Van Keulen \& Young (1977).

A recuperação dos indicadores foi determinada de forma indireta, com base na recuperação fecal, utilizando-se as seguintes equações:

Recuperação de MS fecal = $(\mathrm{g}$ de MS fecal estimada / g MS fecal real) x 100

Gramas MS fecal estimada $=\mathrm{g}$ ingerida do indicador $/ \%$ de indicador nas fezes

A recuperação dos indicadores foi estimada através da equação:

Recuperação do indicador $=(1 /$ Recuperação de MS fecal) x 100

Os coeficientes de digestibilidade (CD) da MS foram obtidos pela fórmula:

CD MS = $100-100 \times(\%$ do indicador no alimento/ $\%$ do indicador nas fezes)

O delineamento utilizado foi em quadrado latino $4 \times 4$, com quatro tratamentos e quatro repetições. As variáveis foram analisadas segundo o modelo matemático:

$$
Y i j k=\mu+T k+P j+A i+e i j k
$$

em que: $Y i j k=$ coeficiente de digestibilidade da MS, MO ou recuperação do indicador referente ao animal i, período j e tratamento $\mathrm{k} ; \mu=$ média geral; $\mathrm{Tk}=$ efeito do tratamento $(\mathrm{k}=25,50,75$ ou $100 \%$ de substituição do milho pela farinha de varredura); $\mathrm{Pj}=$ efeito do período de coleta $(1,2,3,4) ; \mathrm{Ai}=$ efeito do animal $(1$, $2,3,4)$; eijk = erro aleatório associado a cada observação

Os valores médios da recuperação dos indicadores e as médias dos coeficientes de digestibilidade da MS e da MO foram submetidos a contrastes ortogonais e comparados por testes de médias. As análises estatísticas foram realizadas pelo GLM do Statistical Analysis Systems (SAS, 1990).

\section{Resultados e Discussão}

Os valores médios de recuperação fecal dos indicadores CIA, CIDA, FDAI e FDNI, encontram-se na Tabela 3. A utilização da CIA e da FDNI para estimar a produção fecal, não diferiu de $100 \% \mathrm{e}$, portanto, foi semelhante àquela obtida pela coleta total de fezes. Por outro lado, o uso da CIDA e da FDAI diferiu de $100 \%$ e superestimaram a produção fecal.

Os resultados obtidos com a CIA no presente trabalho mostraram-se satisfatórios (média de recuperação de $105,77 \%$ ), para teores de CIA variando de 1,23 a $1,34 \%$ na MS da ração. Estes resultados estão de acordo com Thonney et al. (1979), que encontraram semelhança entre o método de coleta

R. Bras. Zootec., v.31, n.4, p.1865-1874, 2002 
Tabela 3 - Recuperação percentual da cinza insolúvel em ácido (CIA), cinza insolúvel em detergente ácido (CIDA), fibra em detergente ácido indigestível (FDAI) e fibra em detergente neutro indigestível (FDNI) na matéria seca fecal

Table 3 - Percentual recuperation of acid insoluble ash (AIA), acid detergent insoluble ash (ADIA), indigestible acid detergent fiber $(I A D F)$, indigestible neutral detergent fiber (INDF) in fecal dry recuperation

\begin{tabular}{|c|c|c|c|c|c|}
\hline \multirow[t]{2}{*}{$\begin{array}{l}\text { Indicadores } \\
\text { Markers }\end{array}$} & \multicolumn{4}{|c|}{$\begin{array}{l}\% \text { de substituição do MI pela FV } \\
\% \text { replacement of corn by cassava by-product meal }\end{array}$} & \multirow[t]{2}{*}{$\begin{array}{l}\text { Média } \\
\text { Mean }\end{array}$} \\
\hline & R25 & R50 & R75 & R100 & \\
\hline \multicolumn{6}{|c|}{$\begin{array}{l}\text { \% Recuperação do indicador } \\
\text { \% markers recuperation }\end{array}$} \\
\hline $\begin{array}{l}\text { CIA } \\
A I A\end{array}$ & 107,38 & 109,69 & 97,31 & 108,69 & 105,77 \\
\hline $\begin{array}{l}\text { CIDA } \\
A D I A\end{array}$ & 80,56 & 96,33 & 79,67 & 94,82 & $87,84 *$ \\
\hline $\begin{array}{l}\text { FDAI } \\
I A D F\end{array}$ & 98,21 & 89,67 & 81,67 & 89,49 & $89,76^{*}$ \\
\hline $\begin{array}{l}\text { FDNI } \\
I N D F\end{array}$ & 102,31 & 97,00 & 93,74 & 113,41 & 101,61 \\
\hline
\end{tabular}

R25, R50, R75 e R100: respectivamente, 25, 50, 75 e 100\% de farinha de varredura em substituição ao milho. ClA: cinza insolúvel em ácido, CIDA: cinza insolúvel em detergente ácido, FDAI: fibra em detergente ácido indigestível, FDNI: fibra em detergente neutro indigestível.

* Valores diferentes de 100 a 5\% de significância pelo teste de Duncan.

Coeficiente de variação $=15,89 \%$

R25, R50, R75 and R100: respectively, 25, 50, 75 and 100\% of replacement of cassava by-product meal by corn. AIA: acid insoluble ash, ADIA: acid detergent insoluble ash, IADF: indigestible acid detergent fiber, INDF: indigestible neutral detergent fiber.

* Different values of 100 to $5 \%$ significative level by Duncan test.

Coefficient of variation $=15.89 \%$

total e o uso da CIA como indicador, para teores de CIA variando de 0,33 a $0,74 \%$ da MS da ração, concluindo que uma dieta que apresentasse mais que $0,75 \%$ de CIA na ração teria resultados satisfatórios. Também, Carvalho et al. (1992), avaliando o uso da CIA, da lignina e da CIDA para estimar a digestibilidade dos nutrientes de rações, em cabras em lactação alimentadas ad libitum, obtiveram valores de recuperação da CIA de 86,3 a 114,6\%, cujos valores médios não diferiram de $100 \%$, sendo o teor de CIA na dieta de $1,94 \%$.

Entretanto, a literatura mostra grande variação nos resultados observados para a CIA. Oliveira et al. (1991) não obtiveram bons resultados com a CIA, obtendo uma média de recuperação de $85,04 \%$ e $89,04 \%$, respectivamente, para teores de CIA de 1,08 e $1,40 \%$ na MS da ração. As rações continham $50 \%$ e $30 \%$ de concentrado e feno de brachiaria como volumoso. Também, Berchielli et al. (2000) verificaram que a CIA subestimou a digestibilidade em função da baixa recuperação do indicador nas fezes em rações com $1,16 \%$ de CIA.

Por outro lado, Zeoula et al. (1994) observaram valores médios de recuperação fecal da CIA elevados $150,9 \pm 5,9 \%$ e $115,4 \pm 9,8 \%$, para o consumo voluntário e restrito, respectivamente, em ovinos ali- mentados com rações constituídas de 5 ou $20 \%$ de soja crua em grão e feno de aveia. Os teores de CIA na MS da ração foram de 1,53 e 1,31\%, respectivamente. Ainda, Zeoula et al. (2000) avaliaram a CIA, a FDNI e óxido crômico como indicadores, nos estudos de digestibilidade parcial e total em bovinos, recebendo rações com $50 \%$ de concentrado e $50 \%$ de volumoso (silagem de milho) e teor de CIA de 1,45\%. Os autores observaram que os fluxos de MS duodenal e fecal foram subestimados pela CIA e a digestibilidade superestimada, como demonstrado pela maior variação em relação à média e maior variação experimental, quando comparado ao óxido crômico.

Verifica-se que a CIA como indicador de fluxos de MS é ainda satisfatório para determinadas circunstâncias em função dos bons resultados obtidos em vários trabalhos (Van Keulen e Young, 1977; Thonney et al., 1979; Sein e Todd, 1988; Fontes et al., 1996), além de ser de baixo custo. Todavia, os resultados negativos do uso da CIA como indicador, divulgado na literatura, são referentes a fatores que interferem na recuperação da CIA, como a baixa concentração e a composição da CIA na ração, contaminação por areia, uso simultâneo de indicador externo e o próprio método analítico. Ainda especificando melhor estas e outras fontes de variação, pode- 
se citar, tipo de ingrediente adicionado à ração, sobras no cocho (quando os animais são submetidos a consumo voluntário), local de confinamento dos animais (baia ou gaiola metabólica), tipo de cochos (cimento ou de metal galvanizado) e, muitas vezes, a baixa repetibilidade do método analítico da CIA para determinadas amostras.

Com relação à recuperação da FDNI nas fezes, o resultado foi promissor $(101,6 \%)$, mostrando-se eficiente como indicador. Berchielli et al. (2000) também obtiveram bons resultados com o uso da FDNI obtida pela fermentação in vitro por seis dias, não diferindo da digestibilidade dos nutrientes determinada pela coleta total. Todavia, quando os alimentos e as fezes foram incubados durante três dias para estimar os teores da FDNI, verificou-se a baixa recuperação deste, subestimando a digestibilidade.

A recuperação fecal da FDNI in vitro é variável de acordo com o alimento utilizado, o que foi comprovado por Cochran et al. (1986), que verificaram uma variação na digestão desses componentes de acordo com os alimentos utilizados. Segundo esses autores, a aplicabilidade da FDNI in vitro como indicador interno para animais consumindo dietas com forragens deve ser melhor estudada, pois os resultados da digestibilidade da MS obtidos in vivo e pela FDNI in vitro foram variáveis.

Lippke et al. (1986) confirmaram que a variação na recuperação da FDNI é causada por variações no tamanho das partículas dos substratos fermentados e cuidados devem ser tomados para uniformizar o tamanho da partícula do substrato para as fermentações in vitro.

Zeoula et al. (2000) e Ítavo et al. (2002) afirmam que a FDNI subestimou a digestibilidade e apresentou altos coeficientes de variação. Freitas et al. (2001), também não obtiveram resultados eficientes com o uso da FDNI, observando que as estimativas de produção fecal obtida com o uso da FDNI in vitro e FDNI in situ foram sub e superestimadas, respectivamente. Verifica-se que o tamanho de partículas, a composição da fibra, o período de tempo e o modo de incubação (in vitro ou in situ) são fatores de variação que devem ser considerados quando do uso da FDNI como indicador interno.

Em relação à baixa recuperação da CIDA nas fezes de $87,84 \%$, os resultados estão de acordo com Sherrod et al. (1978) e Zeoula et al. (1994), os quais demonstraram que a CIDA não permitiu boa estimativa da digestibilidade quando presente em nível infe- rior a 3\% na ração. Todavia, Oliveira et al. (1991), Carvalho et al. (1992) e Fontes et al. (1996) observaram que a recuperação da CIDA foi semelhante a $100 \%$, mesmo estando os teores de CIDA abaixo de $3 \%$ nas rações. Oliveira et al. (1991) destacaram que o período de coleta inferior a 4 dias foi prejudicial à recuperação fecal da CIDA.

Além da concentração da CIDA nas rações e do período de coleta, que podem influenciar nos resultados, o método analítico da CIDA mais trabalhoso pode aumentar a probabilidade de erro quando comparado à determinação da CIA, o que pode ter refletido em baixa recuperação do indicador nas fezes, no presente trabalho.

A baixa recuperação fecal da FDAI de 89,76\%, em relação à coleta total de fezes, superestimou a produção fecal. Piaggio et al. (1991) também não obtiveram bons resultados de recuperação fecal utilizando FDAI como indicador. Os valores de recuperação variaram de 92,90 a $104,97 \%$, e os autores relataram que, a menor recuperação da FDAI, estaria relacionada aos problemas na filtragem durante as análises ou seria devido à variação associada à digestão in situ, como por exemplo o tamanho do poro da bolsa de náilon utilizada, por onde ocorrem possíveis perdas de fezes.

Entretanto, uma alta recuperação fecal da FDAI de $114,1 \%$, quando comparada à coleta total, foi observada por Saliba et al. (1999) que concluíram que a digestibilidade da ração foi superestimada. Por outro lado, Berchielli et al. (2000) e Ìtavo et al. (2001a) concluíram que a FDAI apresentou resultado semelhante ao da coleta total, na estimativa da digestibilidade.

Os coeficientes de digestibilidade (CD) da matéria seca (MS) e da matéria orgânica (MO) não diferiram em relação ao nível de substituição do milho pela $\mathrm{FV}$, independentemente do indicador interno utilizado (Tabela 4). Como não foi observado efeito do nível de substituição do milho pela $\mathrm{FV}$, os dados foram comparados utilizando-se a média global dos quatro tratamentos. Os valores dos CD da MS e MO, observados com o uso de indicadores internos CIA, FDAI e FDNI, não diferiram $(\mathrm{P}>0,05)$ dos valores observados com o uso do método de coleta total de fezes, para a média dos tratamentos. Vale ressaltar que numericamente, os valores obtidos para os $\mathrm{CD}$ da MS e MO, por meio da CIA e da FDNI, foram semelhantes aqueles obtidos pela coleta total, enquanto que para FDAI embora não diferindo estatis-

R. Bras. Zootec., v.31, n.4, p.1865-1874, 2002 
ticamente, foram menores em aproximadamente quatro unidades percentuais. A digestibilidade da MS e da MO obtida pela FDAI não diferiu daquela obtida pela CIDA, que por sua vez diferiu dos demais indicadores.

A CIA foi considerada no presente trabalho um indicador aceitável, já que os coeficientes de digestibilidade da MS $(69,93 \%)$ e da MO $(71,64 \%)$ foram semelhantes aos resultados obtidos com a coleta total de fezes, respectivamente $69,46 \%$ e $71,17 \%$. Estes resultados estão de acordo com Carvalho et al. (1992). Todavia, Zeoula et al. (1994), Fontes et al. (1996) e Zeoula et al. (2000) não encontraram resultados confiáveis com o uso da CIA, que superestimou os coeficientes de digestibilidade. Já Oliveira et al. (1991) e Piaggio et al. (1991) encontraram resultados que subestimaram os coeficientes de digestibilidade com o uso da CIA como indicador.

A digestibilidade aparente da MS e MO obtida pela CIDA, observada no presente trabalho, foi subestimada, enquanto Zeoula et al. (1994) observaram que a CIDA superestimou a digestibilidade aparente da MS. Estes resultados concordam que a CIDA não foi um bom indicador nas condições utilizadas. No entanto, outros pesquisadores consideraram a CIDA confiável como indicador, como Sherrod et al. (1978), para níveis de CIDA acima de 3\%. Todavia, Oliveira et al. (1991), Carvalho et al. (1992) e Fontes et al. (1996) obtiveram bons resultados na estimativa da digestibilidade da matéria seca com o uso da CIDA, independente do teor de concentrado da dieta, níveis inferiores a $3 \%$ de CIDA e em período de coleta de fezes, a partir de 4 dias.

A FDAI, no presente trabalho, também foi considerado um bom indicador na estimativa dos coeficientes de digestibilidade da MS e da MO. Piaggio et al. (1991), Berchielli et al. (1998), Saliba et al. (1999), Freitas et al. (2001) e Ítavo et al. (2002) mostraram a FDAI como um indicador promissor, uma vez que os valores médios obtidos para digestibilidade da MS foram semelhantes àqueles obtidos pela coleta total de fezes.

Berchielli et al. (2000) também verificaram que o período de incubação de seis ou três dias para a determinação da FDAI influenciou os dados de digestibilidade. Observaram que, com seis dias, não

Tabela 4 - Coeficientes de Digestibilidade (CD) da matéria seca, (MS) matéria orgânica (MO) obtidos pelo método de coleta total de fezes (CT) e do método indireto utilizando indicadores internos

Table 4 - Digestibility coefficients (DC) of dry matter (DM), organic matter (OM), obtained through the total collect methodology of excrements (TC) and indirect method using internal markers

\begin{tabular}{|c|c|c|c|c|c|}
\hline \multirow{3}{*}{$\begin{array}{l}\text { Indicadores } \\
\text { Markers }\end{array}$} & \multicolumn{4}{|c|}{ \% de substituição do MI pela FV } & \multirow{3}{*}{$\begin{array}{l}\text { Média } \\
\text { Mean }\end{array}$} \\
\hline & \multicolumn{4}{|c|}{$\%$ replacement of corn by cassava by-product meal } & \\
\hline & $\mathrm{R} 25$ & $\mathrm{R} 50$ & R75 & R100 & \\
\hline \multicolumn{6}{|c|}{$\begin{array}{l}\text { Coeficiente de digestibilidade da MS } \\
\text { Digestibility coefficient of DM }\end{array}$} \\
\hline $\mathrm{CT}(T C)$ & 69,69 & 69,27 & 70,37 & 68,52 & $69,46^{\mathrm{a}}$ \\
\hline $\operatorname{CIA}(A I A)$ & 69,66 & 71,32 & 68,42 & 70,31 & $69,93^{\mathrm{a}}$ \\
\hline CIDA $(A D I A)$ & 61,00 & 66,98 & 60,49 & 66,08 & $63,64^{\mathrm{b}}$ \\
\hline FDAI $(I A D F)$ & 68,64 & 64,92 & 63,62 & 64,69 & $65,47^{\mathrm{ab}}$ \\
\hline FDNI $(I N D F)$ & 69,92 & 68,04 & 68,25 & 72,04 & $69,56^{\mathrm{a}}$ \\
\hline \multicolumn{6}{|c|}{$\begin{array}{c}\text { Coeficiente de digestibilidade da MO } \\
\text { Digestibility coefficient of } O M\end{array}$} \\
\hline $\mathrm{CT}(T C)$ & 71,47 & 71,46 & 71,69 & 70,07 & $71,17^{\mathrm{a}}$ \\
\hline $\operatorname{CIA}(A I A)$ & 70,49 & 72,71 & 70,34 & 73,02 & $71,64^{\mathrm{a}}$ \\
\hline CIDA (ADIA) & 62,79 & 68,44 & 61,95 & 67,65 & $65,21^{\mathrm{b}}$ \\
\hline FDAI $(I A D F)$ & 70,11 & 66,48 & 65,07 & 66,32 & $67,00^{\mathrm{ab}}$ \\
\hline FDNI (INDF) & 71,35 & 68,81 & 69,53 & 73,34 & $70,76^{\mathrm{a}}$ \\
\hline
\end{tabular}

R25, R50, R75 e R100: respectivamente, 25, 50, 75 e 100\% de farinha de varredura em substituição ao milho. CIA: cinza insolúvel em ácido, CIDA: cinza insolúvel em detergente ácido, FDAl: fibra em detergente ácido indigestível, FDNI: fibra em detergente neutro indigestível.

Médias na coluna, seguidas de letras diferentes, diferem entre si $(P<0,05)$ pelo teste de Tukey.

Coeficiente de variação do $\mathrm{CD}$ da $\mathrm{MS}=7,70 \%$; do $\mathrm{CD}$ da $\mathrm{MO}=6,82 \%$.

R25, R50, R75 and R100: respectvely, 25, 50, 75 and 100\% of replacement of cassava by-product meal by corn. AlA: acid insoluble ash, ADIA: acid detergent insoluble ash, IADF: indigestible acid detergent fiber, INDF: indigestible neutral detergent fiber.

Means in column, followed by different letters, are different $(P<.05)$ by Tukey test.

coefficient of variation of $D C$ by $D M=7.70 \%$; $D C$ by $O M=6.82 \%$.

R. Bras. Zootec., v.31, n.4, p.1865-1874, 2002 
houve diferença entre os dados obtidos pelo indicador e aqueles obtidos pela coleta total e com três dias de incubação subestimou a digestibilidade dos nutrientes. Isso demonstra a ocorrência de diferença na digestibilidade dos nutrientes, quando as amostras são incubadas por menor tempo, principalmente para a matéria seca, não reproduzindo realmente a fração indigestível do indicador. Portanto, com tempo maior de incubação, há maior reprodução da digestibilidade no trato digestivo inferior, o que concorda com Van Soest (1994), o qual relata que indicadores internos necessitam de maior tempo de incubação.

As estimativas dos coeficientes de digestibilidade da MS $(69,56 \%)$ e da MO (70,76\%) obtidos pela FDNI foram semelhantes àqueles da coleta total, respectivamente, 69,46 e $71,17 \%$. Estes resultados concordam com os dados obtidos por Berchielli et al. (1998) e Berchielli et al. (2000). No entanto, Zeoula et al. (2000) e Ítavo et al. (2001a) não encontraram resultados aceitáveis com este indicador, pois a FDNI subestimou a digestão ruminal e a digestibilidade total da MS e da MO e apresentou maior variação experimental.

\section{Conclusões}

Os resultados obtidos no presente trabalho permitem concluir que a cinza insolúvel em ácido (CIA) e a fibra em detergente neutro indigestivel (FDNI), foram os indicadores mais eficientes, uma vez que seus valores de recuperação fecal não diferiram de $100 \%$, quando comparados a coleta total de fezes. A cinza insolúvel em detergente ácido (CIDA) e a fibra em detergente ácido (FDAI) apresentaram valores de recuperação que diferiram de $100 \%$.

A CIA, a FDNI e a FDAI mostraram-se indicadores adequados na estimativa da digestibilidade da MS e da MO, com coeficientes semelhantes aqueles obtidos pelo método de coleta total de fezes.

\section{Literatura Citada}

BERCHIELLI, T.T.; ANDRADE, P.; FURLAN, C.L.. Avaliação de indicadores internos em ensaios de digestibilidade. Revista da Sociedade Brasileira de Zootecnia, v.29, n.3, p.830-833, 2000.

BERCHIELLI, T.T.; RODRIGUEZ, N.M.; OSÓRIO NETO, E. et al. Comparação de marcadores de fase sólida para medir fluxo de matéria seca e matéria orgânica no duodeno. Arquivos Brasileiro de Medicina Veterinária e Zootecnia, v.50, n.2, p.147-152,1998.

CARVALHO, F.F.R.; QUEIROZ, A.C.; RODRIGUEZ, M.T. et al. Uso de indicadores internos para estimar a digestibilidade dos nutrientes das rações para cabras em lactação alimentadas ad libitum. Revista da Sociedade Brasileira de Zootecnia, v.21, n.2, p.270-278, 1992.

COCHRAN, R.C.; ADAMS, D.C.; WALLACE, J.D. et al. Predicting digestibility of different diets with internal markers. Journal Animal Science, v.63, n.5, p.1476-1483, 1986.

COELHO DA SILVA, J.F.; LEÃO, M.I. Fundamentos de nutrição dos ruminantes. Piracicaba: Livroceres, 1979. $384 \mathrm{p}$.

EZEQUIEL, J.M.B.; MENDES, A.R.; SILVA, L.D.F. et al. Estimativa da digestibilidade através da FDN indigestível de rações contendo dois níveis de casca de soja e diferentes fontes protéicas em novilhos mestiços. In: REUNIÃO ANUAL DA SOCIEDADE BRASILEIRA DE ZOOTECNIA, 36 1999, Porto alegre. Anais...Porto Alegre: SBZ/Gnosis [1999]. CD-ROM.

FONTES, C.A.A.; OLIVEIRA, M.A.T.; LANA, R.P. Avaliação de indicadores na determinação da digestibilidade em novilhos. Revista da Sociedade Brasileira de Zootecnia, v.25, n.3, p.529-539, 1996.

FREITAS, D.; BERCHIELLI, T.T.; SILVEIRA, R.N. et al. Produção fecal e fluxo duodenal de matéria seca estimados através de indicadores. In: REUNIÃO ANUAL DA SOCIEDADE BRASILEIRA DE ZOOTECNIA, 38., 2001, Piracicaba. Anais... Piracicaba: Sociedade Brasileira de Zootecnia, 2001. p.1114.

ÍTAVO, L.C.V.; SILVA, F.F.; VALADARES FILHO, S.C. et al. Indicadores internos para estimativas de produção fecal e digestibilidade de nutrientes em bovinos. In: REUNIÃO ANUAL DA SOCIEDADE BRASILEIRA DE ZOOTECNIA, 38., 2001, Piracicaba. Anais...Piracicaba: Sociedade Brasileira de Zootecnia, 2001a. p.1028.

ÍTAVO, L.C.V.; SILVA, F.F.; VALADARES FILHO, S.C. et al. Digestibilidade aparente total e parcial em novilhos nelore através de indicadores interno ou externo. In: REUNIÃO ANUAL DA SOCIEDADE BRASILEIRA DE ZOOTECNIA, 38., 2001, Piracicaba. Anais... Piracicaba: Sociedade Brasileira de Zootecnia, 2001b. p.1039.

ÍTAVO, L.C.V.; VALADARES FILHO, S.C.; SILVA, F.F. et al. Consumo, degradabilidade ruminal e digestibilidade aparente de fenos de gramíneas do gênero Cynodon e rações concentradas utlizando indicadores internos. Revista Brasileira de Zootecnia, v.31, n.2, p.1024-1032, 2002

LIPPKE, H.; ELLIS, W.C.; JACOBS, B.F. Recovery of indigestible fiber from feces of sheep and cattle on forrage diets. Journal Animal Science, v.69, n.2, p.403-413, 1986.

MERCHEN, N.R. Digestion, absorption and excretion in ruminantes In: CHURCH, D.C. (Ed.) The ruminant animal digestive physiology and nutrition. 4.ed. Carvallis: O\&B Books. 1993. p.172-201.

NATIONAL RESEARCH COUNCIL - NRC. Nutrient requirements of sheep. 5.ed. Washington, D.C.: 1975. 69p.

OLIVEIRA, R.F.M.; FONTES, C.A.L.; COELHO DA SILVA, J.F. et al. Estudo da recuperação fecal do óxido crômico e dos indicadores internos CIA, CIDA e lignina em períodos de coleta de dois a sete dias, em bovinos. Revista da Sociedade Brasileira de Zootecnia, v.20, n.5, p.522-531, 1991.

PIAGGIO, L.M.; PRATES, E.R.; PIRES, F.F. et al. Avaliação das cinzas insolúveis em ácido, fibra em detergente ácido indigestível e lignina em detergente ácido indigestível como indicadores internos da digestibilidade. Revista da Sociedade Brasileira de Zootecnia, v.20, n.3, p.306-312, 1991. 
SALIBA, E.O.S.; RODRIGUEZ, N.M.; GONÇALVES, L.C. Estudo comparativo da lignina isolada da palha de milho, com outros indicadores em ensaio de digestibilidade aparente. In: REUNIÃO ANUAL DA SOCIEDADE BRASILEIRA DE ZOOTECNIA, 36., 1999, Porto Alegre. Anais... Porto Alegre: Sociedade Brasileira de Zootecnia, 1999. p.293.

SEIN, T.; TODD, J.R. Investigations into the use of indicator methods of estimating the digestibilities of fods by ruminant animals. Journal of Agricultural Science, v.110, n.2, p.315-320, 1988 .

SHERROD, L.B.; SUMMERS, C.B.; ALBIN, R.C. et al. ADF insoluble ash, $\mathrm{HCl}$ insoluble ash and lignin as indicators for determining ruminant digestibility. Proceedings Western Section American Society of Animal Science, v.29, n.5, p.236-242, 1978.

SILVA, D.J. Análise de alimentos: métodos químicos e biológicos. 2.ed. Viçosa, MG: Universidade Federal de Viçosa, 1990. $165 \mathrm{p}$

STATISTICAL ANALYSIS INSTITUTE. SAS user's guide: statistic version. 5.ed. Cary: 1990. 956p.

THONNEY, M.L.; DUHAIME, D.J.; MOE, P.W. et al. Acid insoluble ash and permanganate lignin as indicators to determine digestibility of cattle rations. Journal of Animal Science, v.49, n.4, p.112-1146, 1979
Van KEULEN, J.; YOUNG, B.A. Evaluation of acid-insoluble ash as a natural marker in ruminant digestibility studies Journal of Animal Science, v.44, n.2, p.238-287, 1977.

Van SOEST, P.J. Nutritional ecology of the ruminant. 2.ed. New York: Cornell University Press, 1994. 476p.

ZEOULA, L.M., BRANCO, A.F., SALINA, L.J. Avaliação de indicadores em estudo de digestibilidade de alimentos para ruminantes. Revista Unimar, v.22, n.3, p.165-174, 1994.

ZEOULA, L.M.; COELHO DA SILVA, J.F.; LEÃO, M.I. et al. Utilização de CIA, óxido crômico e celulose em estudos de digestão. Revista da Sociedade Brasileira de Zootecnia, v.21, n.2, p.73-82, 1992.

ZEOULA, L.M.; KASSIES, M.P.; FREGADOLLI, F.L. et al. Uso de indicadores na determinação da digestibilidade parcial e total em bovinos. Acta Scientiarum, v.22, n.3, p.771-777, 2000. 